\title{
Spinal arachnoid cysts in adults: diagnosis and management. A single-center experience
}

\author{
Maged D. Fam, MD, ${ }^{1}$ Royce W. Woodroffe, MD, ${ }^{1}$ Logan Helland, MD, ${ }^{1}$ Jennifer Noeller, ARNP, 1 \\ Nader S. Dahdaleh, MD, ${ }^{2}$ Arnold H. Menezes, MD, ${ }^{1}$ and Patrick W. Hitchon, MD ${ }^{1}$

\begin{abstract}
'Department of Neurosurgery, University of lowa Hospitals and Clinics, lowa City, lowa; and 2Department of Neurosurgery, Northwestern University, Feinberg School of Medicine, Chicago, Illinois
\end{abstract}

\begin{abstract}
OBJECTIVE Adult spinal arachnoid cysts (SACs) are rare entities of indistinct etiology that present with pain or myelopathy. Diagnosis is made on imaging studies with varying degrees of specificity. In symptomatic cases, the standard treatment involves surgical exploration and relief of neural tissue compression. The aim of this study was to illustrate features of SACs in adults, surgical management, and outcomes.

METHODS The authors searched medical records for all SACs in adults in the 10-year period ending in December 2016. Radiology and pathology reports were reviewed to exclude other spine cystic disorders. Recurrent or previously treated patients were excluded. Demographic variables (age, sex) and clinical presentation (symptoms, duration, history of infection or trauma, and examination findings) were extracted. Radiological features were collected from radiology reports and direct interpretation of imaging studies. Operative reports and media were reviewed to accurately describe the surgical technique. Finally, patient-reported outcomes were collected at every clinic visit using the SF-36.

RESULTS The authors' search identified 22 patients with SACs (mean age at presentation 53.5 years). Seventeen patients were women, representing an almost 3:1 sex distribution. Symptoms comprised back pain $(n=16,73 \%)$, weakness $(n=10,45 \%)$, gait ataxia $(n=11,50 \%)$, and sphincter dysfunction $(n=4,18 \%)$. The mean duration of symptoms was 15 months. Seven patients (32\%) exhibited signs of myelopathy. All patients underwent preoperative MRI; in addition, 6 underwent CT myelography. SACs were located in the thoracic spine $(n=17,77 \%)$, and less commonly in the lumbar spine $(n=3,14 \%)$ and cervical/cervicothoracolumbar region $(n=2,9 \%)$. Based on imaging findings, the cysts were interpreted as intradural SACs $(n=11,50 \%)$, extradural SACs $(n=6,27 \%)$, or ventral spinal cord herniation $(n=2,9 \%)$; findings in 3 patients $(14 \%)$ were inconclusive. Nineteen patients underwent surgical treatment consisting of laminoplasty in addition to cyst resection $(n=13,68 \%)$, ligation of the connecting pedicle $(n=4,21 \%)$, or fenestration/marsupialization $(n=2$, $11 \%$ ). Postoperatively, patients were followed up for an average of 8.2 months (range 2-30 months). Postoperative MRI showed complete resolution of the SAC in 14 of 16 patients. Patient-reported outcomes showed improvement in SF-36 parameters. One patient suffered a delayed wound infection.
\end{abstract}

CONCLUSIONS In symptomatic patients with imaging findings suggestive of spinal arachnoid cyst, surgical exploration and complete resection is the treatment of choice. Treatment is usually well tolerated, carries low risks, and provides the best chances for optimal recovery.

https://thejns.org/doi/abs/10.3171/2018.5.SPINE1820

KEYWORDS arachnoid cysts; meningeal cysts; meningocele; spinal cysts; congenital

$\mathrm{S}$ PINAL arachnoid cysts (SACs) in adults are rare pathological entities that often present with back pain or myelopathy. Theories on the pathogenesis of these cysts, suggesting that they arise from diverticula in the septum posticum or ectopic arachnoid granulations, have not been substantiated..$^{5,13,19-21}$ In most cases, no underly- ing cause for the SAC can be identified and is considered as an idiopathic SAC. In some cases, SACs can develop from arachnoid adhesions following trauma or inflammatory or infectious causes. Surgical etiologies of arachnoid cysts have also been described after conducting various procedures, such as a lumbar myelography, laminectomy,

ABBREVIATIONS mJOA = modified Japanese Orthopaedic Association; $\mathrm{SAC}=$ spinal arachnoid cyst; $\mathrm{VSCH}=$ ventral spinal cord herniation

SUBMITTED January 4, 2018. ACCEPTED May 22, 2018.

INCLUDE WHEN CITING Published online September 28, 2018; DOI: 10.3171/2018.5.SPINE1820. 

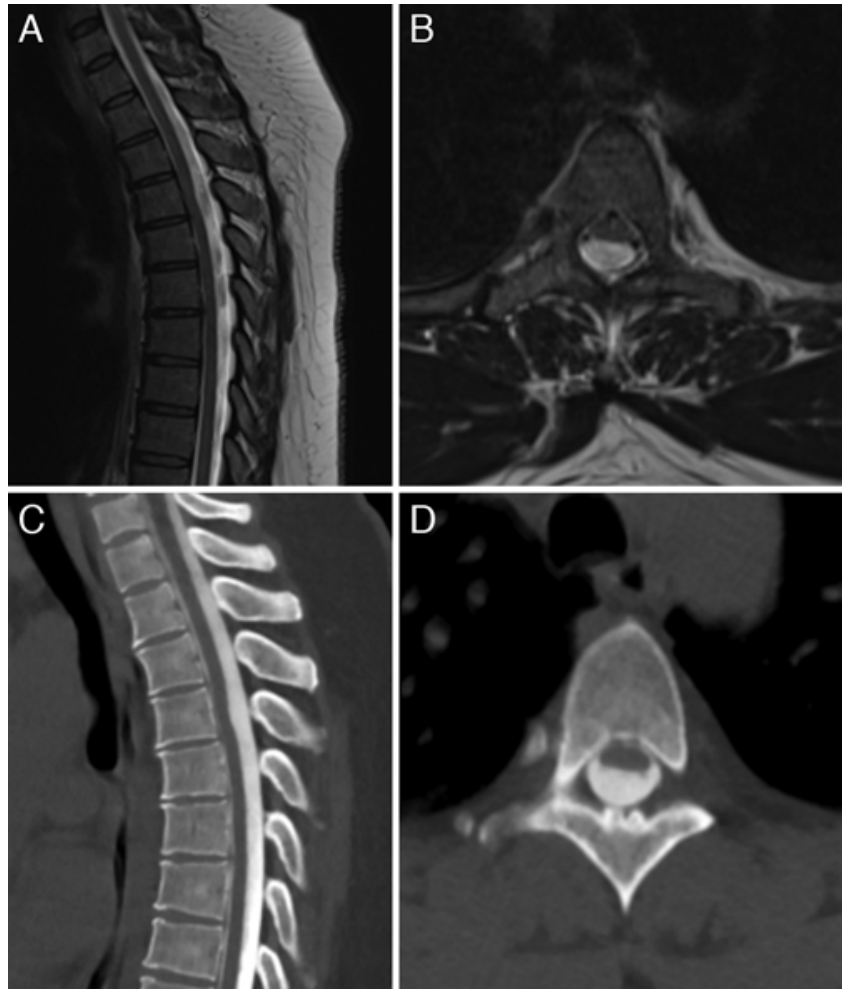

FIG. 1. Case 5. A 45-year-old woman presented with a 2-year history of worsening midback pain and lower-extremity weakness. Sagittal (A) and axial (B) T2-weighted MR images showing ventral displacement of thoracic spinal cord. Sagittal (C) and axial (D) CT myelography findings are inconclusive and cannot rule out the possibility of cord herniation. Surgical exploration revealed a dorsal arachnoid cyst, which was completely resected.

and vertebroplasty. ${ }^{12,17}$ Inflammatory adhesions within the arachnoid are known to form arachnoid webs that can result in direct cord compression and myelopathy. Such adhesions can also form a 1-way valve entrapping circulating CSF, ultimately resulting in the formation of an SAC. 19,23 Diagnosis is usually suspected on MRI with focal displacement/buckling of the spinal cord and less frequently on direct visualization of a cystic structure within the spinal canal with signal characteristics similar to those of CSF.22 Better delineation can often be obtained through CT myelography, which, in addition to diagnosis, can gauge the degree of free-flowing CSF between the arachnoid cyst and the main subarachnoid space. ${ }^{4}$ Management consists of surgical exploration and decompression via total cyst excision, marsupialization, fenestration, ligation of the communication site, or shunting, or a combination of these techniques. Limited series have been published on SACs in adults, and little is known about their natural course and optimal management. The aim of this study was to illustrate features of spinal arachnoid cysts in adults including surgical management and outcomes.

\section{Methods}

We searched medical records for all adult patients (> 18 years) with a diagnosis of arachnoid cyst or spinal cyst
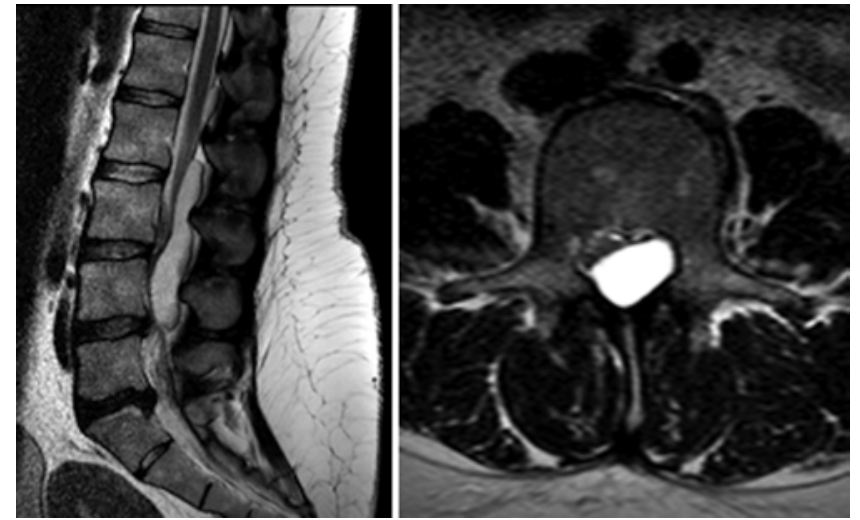

FIG. 2. Case 17. A 34-year-old woman presented with a 2-year history of worsening low-back pain and lower-extremity paresthesia. Sagittal (left) and axial (right) T2-weighted MR images showing a lumbar dorsal extradural cyst, resulting in ventral displacement and compression of the thecal sac.

in the 10-year period from January 2007 to December 2016. Radiological reports were individually reviewed, and all patients with radiological reports including spinal arachnoid cysts of the spine were included. We excluded other cystic disorders of the spine, such as syrinx, hydromyelia, and cystic tumors. Patients with recurrent or previously treated arachnoid cysts were also excluded as well as patients who were lost to follow-up. For all included patients, we extracted demographic variables (age at presentation, sex) and clinical presentation (medical comorbidities, presenting symptoms, duration of symptoms, and examination findings). All surgically treated patients underwent clinical follow-up at 6 weeks postoperatively, at 3 and 6 months, and then annually as dictated by clinical progress. Radiological features of the arachnoid cyst were collected from formal radiology report and direct interpretation of imaging studies by the senior author (P.W.H.). In patients who underwent surgical treatment, operative reports and intraoperative photomicrographs were reviewed to accurately describe and confirm the surgical technique.

Finally, subjective outcomes were collected at every clinical visit using the SF-36. ${ }^{30}$ Scores from the initial clinic visit and the last follow-up visit were available for 15 surgically treated patients and were used to elucidate patient-reported outcomes.

\section{Surgical Treatment}

Patients were selected for surgery based on the degree of symptoms and correlation to imaging findings (Figs. 1 and 2). Intraoperative fluoroscopy was used in all cases to identify spinal level, and laminoplasty was then undertaken under electrophysiological monitoring for somatosensory and motor evoked potentials. Exposure was tailored to expose the entire SAC whenever possible, exposing the caudal and rostral boundaries. Tack-up dural sutures were then placed, and the cyst wall was dissected free from the surrounding dura and cord and then resected (Fig. 3). In the case of extradural cysts (Fig. 2), these were also exposed via laminoplasty and dissected free of their 

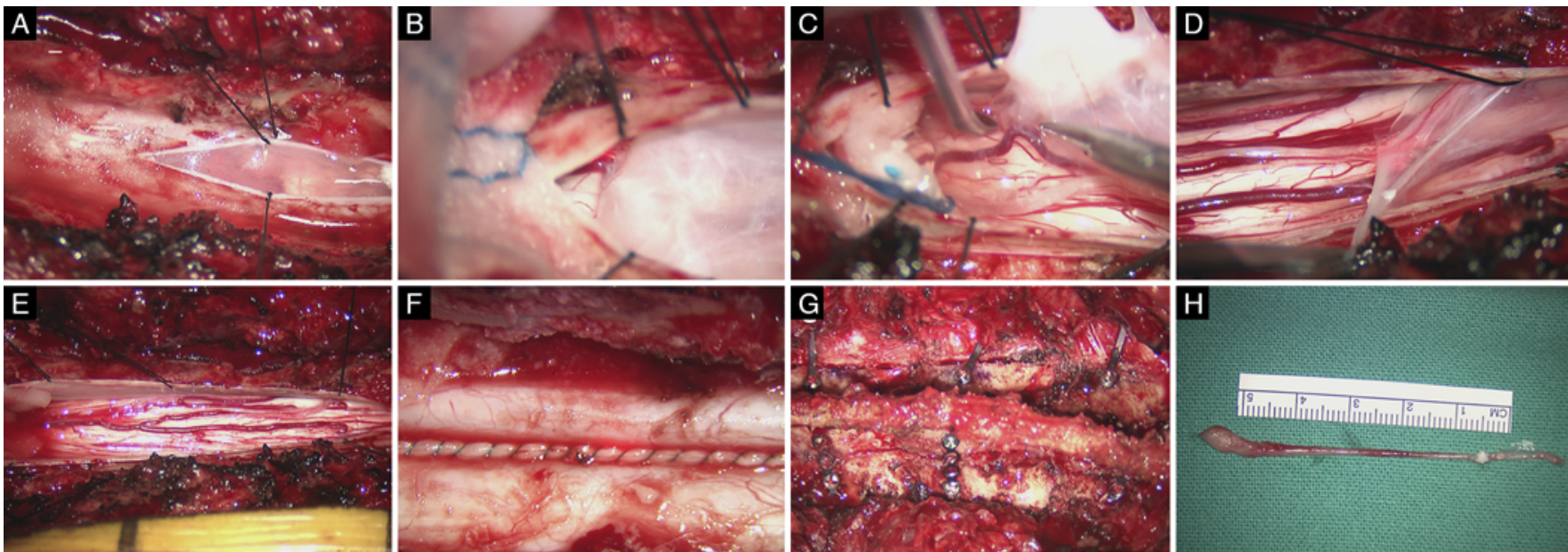

FIG. 3. Surgical exploration and midline durotomy revealing a dorsal thoracic intradural arachnoid cyst (A), with the cyst dome identified caudally (B). The cyst is dissected and excised (C and D). After complete cyst excision, the spinal cord is clearly visualized without the opacity of the cyst $(\mathbf{E})$. The durotomy is then repaired $(\mathbf{F})$ and the laminoplasty closed $(\mathbf{G})$. The deflated cyst was resected in its entirety $(\mathbf{H})$. Figure is available in color online only.

surroundings, and the pedicle of communication with the subarachnoid space was ligated before resection of the cyst (Fig. 4). Finally, the laminae were replaced and fixed in place with titanium plates and screws.

\section{Results}

\section{Demographic and Clinical Features}

Twenty-two previously untreated patients with SACs were identified from our database. The mean age at presentation was 53.5 years (range 34-91 years). Seventeen patients were women, demonstrating a sex distribution exceeding a 3:1 ratio. The commonest presenting complaint was midback pain $(\mathrm{n}=13,64 \%)$, followed by recurrent falls $(n=6,27 \%)$ and lower-extremity paresthesia $(n=3$, $14 \%)$. Symptoms reported at the initial clinical encounter comprised back pain $(\mathrm{n}=16,73 \%)$, lower-extremity weakness $(n=10,45 \%)$, loss of coordination $(n=11,50 \%)$, and sphincter disorder $(\mathrm{n}=4,18 \%)$. The mean duration of symptoms was 15 months (range 2-48 months). On clinical examination 7 patients (32\% of all cases and $37 \%$ of cervical and thoracic cysts) exhibited clinical signs of cord
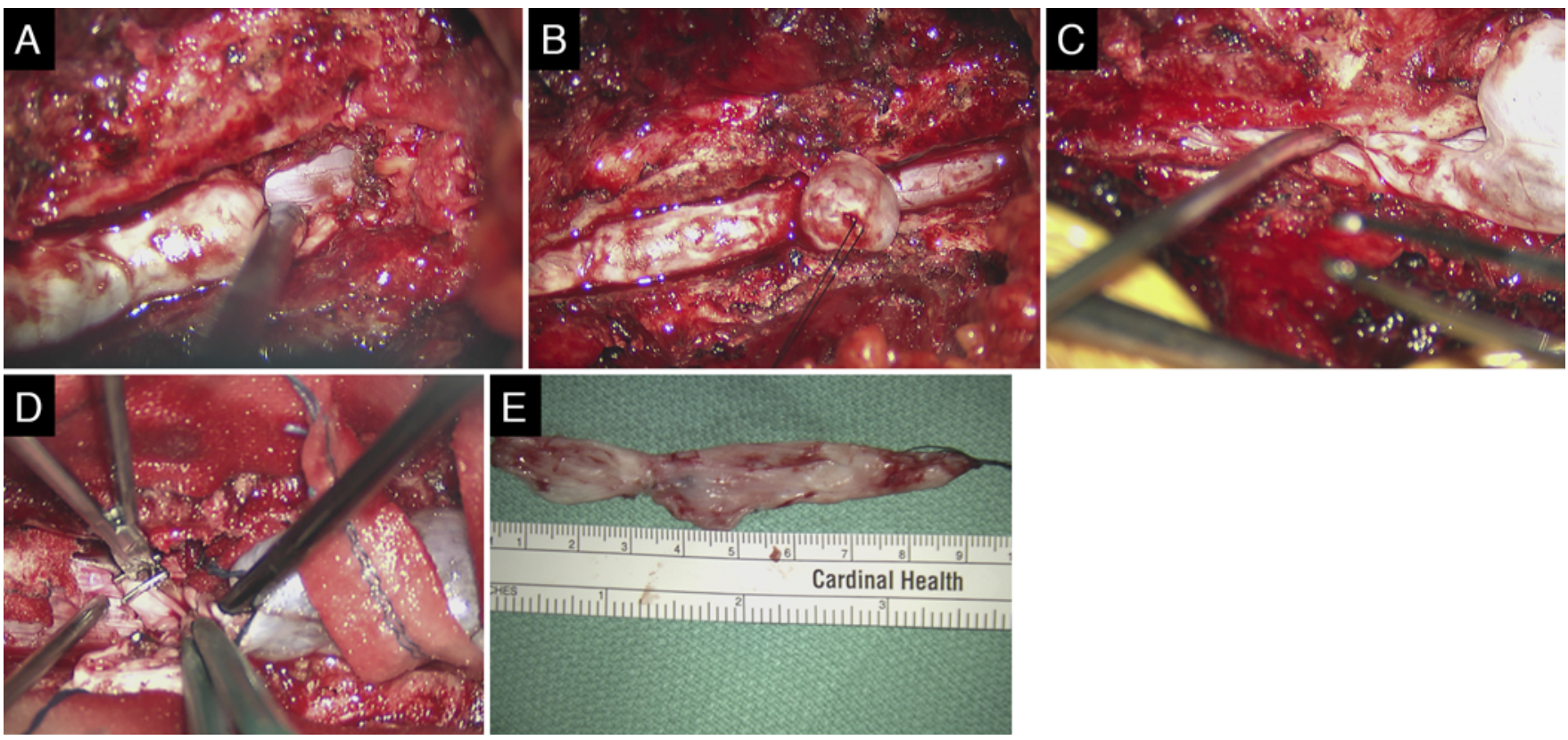

FIG. 4. Surgical exploration of a dorsal extradural arachnoid cyst (A). After cyst dissection, a communicating transdural conduit was identified (B and $\mathbf{C}$ ), and is shown encircled by a right-angle dissector. The communicating pedicle is eventually ligated with hemoclips, transected, and excised ( $\mathbf{D}$ and $\mathbf{E})$. Figure is available in color online only. 
TABLE 1. Demographic and clinical features of patients included in this series

\begin{tabular}{|c|c|c|c|c|c|c|c|c|}
\hline Case No. & Age (yrs), Sex & Presenting Complaint & Duration (mos) & Pain & Weakness & Gait Ataxia & Sphincter & Signs of Myelopathy \\
\hline 1 & $75, \mathrm{~F}$ & Falls & 48 & No & Yes & Yes & Yes & Yes \\
\hline 2 & $57, \mathrm{M}$ & Back pain & 12 & Yes & No & Yes & No & No \\
\hline 3 & $62, \mathrm{~F}$ & Back pain & 12 & Yes & No & No & No & No \\
\hline 4 & $52, \mathrm{M}$ & Falls & 6 & No & No & Yes & Yes & Yes \\
\hline 5 & $45, \mathrm{~F}$ & Back pain & 24 & Yes & Yes & No & No & No \\
\hline 6 & $48, F$ & Back pain & 24 & Yes & Yes & Yes & No & No \\
\hline 7 & $47, \mathrm{~F}$ & Back pain & 24 & Yes & Yes & No & No & No \\
\hline 8 & $38, F$ & Back pain & 2 & Yes & No & No & No & Yes \\
\hline 9 & $49, \mathrm{~F}$ & Paresthesia & 4 & No & No & No & No & No \\
\hline 10 & $73, \mathrm{~F}$ & Back pain & 24 & Yes & Yes & Yes & No & No \\
\hline 11 & $56, F$ & Back pain & 12 & Yes & No & No & Yes & Yes \\
\hline 12 & $51, \mathrm{~F}$ & Falls & 3 & No & Yes & Yes & No & No \\
\hline 13 & $53, \mathrm{~F}$ & Falls & 8 & No & Yes & Yes & No & Yes \\
\hline 14 & $91, \mathrm{M}$ & Falls & 24 & Yes & Yes & Yes & Yes & No \\
\hline 15 & $40, M$ & Back pain & 36 & Yes & No & Yes & No & No \\
\hline 16 & $75, \mathrm{~F}$ & Back pain & 12 & Yes & No & No & No & No \\
\hline 17 & $34, F$ & Paresthesia & 1 & Yes & No & No & No & No \\
\hline 18 & $46, M$ & Back pain & 24 & Yes & No & No & No & No \\
\hline 19 & $46, F$ & Paresthesia & 3 & Yes & Yes & Yes & No & Yes \\
\hline 20 & $57, \mathrm{~F}$ & Falls & 8 & No & Yes & Yes & No & Yes \\
\hline 21 & $19, \mathrm{~F}$ & Back pain & 9 & Yes & No & No & No & No \\
\hline 22 & $62, \mathrm{~F}$ & Back pain & 6 & Yes & No & No & No & No \\
\hline
\end{tabular}

compression, including lower-extremity stiffness, hyperactive reflexes, ankle clonus, and/or loss of proprioception (Table 1). Three patients with an SAC were deemed sufficiently asymptomatic to warrant nonoperative treatment and observation.

\section{Radiological Features}

All patients in our series underwent MRI at the time of presentation. MRI identified the abnormal focal displacement/buckling of the spinal cord or thecal sac. The distribution of these cysts was thoracic in 17 (77\%), lumbar in 3 (14\%), and cervical/cervicothoracolumbar in 2 $(9 \%)$. Ten patients $(45 \%)$ had associated intrinsic cord signal changes or myelomalacia, and 2 patients $(9 \%)$ exhibited a small associated syrinx. When MRI findings were deemed inconclusive of an SAC, 6 patients underwent CT myelography; 3 of these studies pointed to a diagnosis of arachnoid cyst, another 2 favored ventral spinal cord herniation, and 1 accurately identified an extradural arachnoid cyst with a communicating transdural conduit (Fig. 2). Combining the 2 modalities of MRI and myelography, preoperative radiological diagnoses comprised intradural arachnoid cyst $(n=11,50 \%)$, extradural arachnoid cyst $(n=6,27 \%)$, or ventral spinal cord herniation (VSCH; $n=2,9 \%$ ); findings in 3 patients (14\%) were inconclusive.

\section{Surgical Treatment}

Three patients in our series were managed conserva- tively, whereas 19 underwent surgical treatment (Table 2). All surgical procedures were performed by a single senior surgeon (P.W.H.). In all cases, the cyst was exposed via a posterior-approach laminoplasty spanning the entire lesion for an average of 4 levels (range 2-7 levels). The cyst could then be identified using ultrasound and direct inspection after durotomy (Figs. 3 and 4). If a dorsal arachnoid cyst could not be identified despite its suggestion on preoperative imaging, the same approach was then used to inspect the canal ventral to the cord in search of a ventral SAC or VSCH. Dorsal extradural cysts ( $\mathrm{n}=$ 4) were encountered immediately after reflection of the laminae. Those were carefully dissected and resected in their entirety. In all cases of extradural cysts, a transdural pedicle/conduit connecting the cyst to the main subarachnoid space could be identified intraoperatively and was ligated (Fig. 4). For dorsal intradural cysts $(n=12)$, midline durotomy and tack-up sutures allowed identification of the cyst dorsal to the spinal cord. Blunt dissection of the cyst avoids violation of the cyst wall so that the cyst can be well visualized in its entirety. In most cases, arachnoid mater forming the cyst wall is thickened and milky white, allowing its identification and excision (Fig. 3). The ventral cysts that were surgically treated $(n=3)$ required extension of the surgical approach via drilling of the medial portion of the ipsilateral facet joints. In the lumbar spine, retraction of the thecal sac allowed for complete resection of a limited ventral extradural arachnoid cyst (case 6). Another 2 ventral arachnoid cysts in our series extended over multiple levels along the cervical and thoracic spine. 
TABLE 2. Radiological features and operative findings for patients included in this series

\begin{tabular}{|c|c|c|c|c|c|c|c|}
\hline \multirow[b]{2}{*}{ Case No. } & \multirow[b]{2}{*}{ MRI Dx } & \multirow[b]{2}{*}{ CT Myelography Dx } & \multirow[b]{2}{*}{ Extension } & \multicolumn{2}{|c|}{ Anatomical Location } & \multirow[b]{2}{*}{ Treatment } & \multirow[b]{2}{*}{$\mathrm{FU}(\mathrm{mos})$} \\
\hline & & & & Dorsal/Ventral & Extra-/Intradural & & \\
\hline 1 & $\mathrm{AC}$ or VSCH & & T2-4 & Dorsal & Intradural & Resection & 5 \\
\hline 2 & $\mathrm{AC}$ or $\mathrm{VSCH}$ & VSCH & T5-7 & Dorsal & Intradural & Resection & 14 \\
\hline 3 & $\mathrm{AC}$ & & L1-3 & Dorsal & Intradural & Resection & 2 \\
\hline 4 & $A C$ & & C3-6 & Dorsal & Intradural & Resection & 5 \\
\hline 5 & $\mathrm{AC}$ or $\mathrm{VSCH}$ & VSCH & T4-5 & Dorsal & Intradural & Resection & 6 \\
\hline 6 & $\mathrm{AC}$ & & L4-6 & Ventral & Extradural & Resection & 8 \\
\hline 7 & $A C$ & & $\mathrm{~T} 1-6$ & Dorsal & Extradural & Resection/ligation & 2 \\
\hline 8 & $A C$ & & T5-12 & Dorsal & Intradural & Resection & 30 \\
\hline 9 & $\mathrm{AC}$ or $\mathrm{VSCH}$ & & T2-4 & Dorsal & Intradural & Observation & 4 \\
\hline 10 & $\mathrm{AC}$ & & T5-7 & Ventral & Intradural & Observation & 9 \\
\hline 11 & $\mathrm{AC}$ or VSCH & $\mathrm{AC}$ or VSCH & T2-4 & Dorsal & Intradural & Resection & 6 \\
\hline 12 & $\mathrm{AC}$ & & T2-7 & Dorsal & Intradural & Resection & 14 \\
\hline 13 & $A C$ & $A C$ & T4-L3 & Ventral & Intradural & Marsupialization & 6 \\
\hline 14 & VSCH & & T5-6 & Dorsal & Intradural & Resection & 13 \\
\hline 15 & $A C$ & $A C$ & C3-L3 & Ventral & Extradural & Marsupialization & 9 \\
\hline 16 & $\mathrm{VSCH}$ & & T8-10 & Dorsal & Intradural & Resection & 3 \\
\hline 17 & $\mathrm{AC}$ & & L2-4 & Dorsal & Extradural & Resection/ligation & 3 \\
\hline 18 & $A C$ & & T11-12 & Dorsal & Extradural & Resection/ligation & 4 \\
\hline 19 & $A C$ & & C7-T3 & Dorsal & Intradural & Resection & 6 \\
\hline 20 & $A C$ & & T3-8 & Dorsal & Intradural & Resection & 12 \\
\hline 21 & $A C$ & & T12-L1 & Dorsal & Extradural & Resection/ligation & 6 \\
\hline 22 & $A C$ & $A C$ & T3-8 & Dorsal & Intradural & Observation & 60 \\
\hline
\end{tabular}

$\mathrm{AC}=$ arachnoid cyst; $\mathrm{Dx}=$ diagnosis; $\mathrm{FU}=$ follow-up.

Adequate exposure and dissection was therefore technically difficult, and both were fenestrated/marsupialized (cases 13 and 15).

\section{Outcomes}

In patients who did not undergo surgery, a watchful waiting strategy was adopted, with interval clinical and radiological evaluation. There was no clinical or radiological progression at last follow-up. Patients who underwent surgery in our series underwent follow-up at 6 weeks, at 3 and 6 months, and then annually thereafter based on clinical outcome, with a mean follow-up of 8.2 months (range 2-30 months). Postoperative MRI scans were obtained in 16 patients. Postoperative imaging showed residual cyst in 2 patients with ventral SACs that underwent marsupialization. In the remaining patients, complete resolution of the SAC and relaxation of the spinal cord was radiologically confirmed (Fig. 5). Patient-reported outcomes were routinely collected at each clinical encounter using the SF-36. ${ }^{30}$ In surgically treated patients, scores obtained at the last clinic follow-up visit were individually compared with those at presentation. Pre- and postoperative scores were available for 15 patients. Direct comparison showed improvement in SF-36 parameters across all domains: average increase in physical functioning ( 8.4 points, $23 \%$ ), physical limitation (22.2 points, $30 \%$ ), emotional limitation (2.2 points, $17 \%)$, energy/fatigue (4.2 points, $21 \%$ ), emotional well-being (4.1 points, 9\%), social functioning (10.7 points, $31 \%)$, pain (5.7 points, $26 \%$ ), and general health (1.7 points, $2 \%)$. Surgical complications were encountered in 1 patient with a delayed wound infection that was treated conservatively.

\section{Discussion}

\section{Demographic and Clinical Features}

Spinal arachnoid cysts represent a peculiar pathological entity in the differential diagnosis of spinal cystic le-
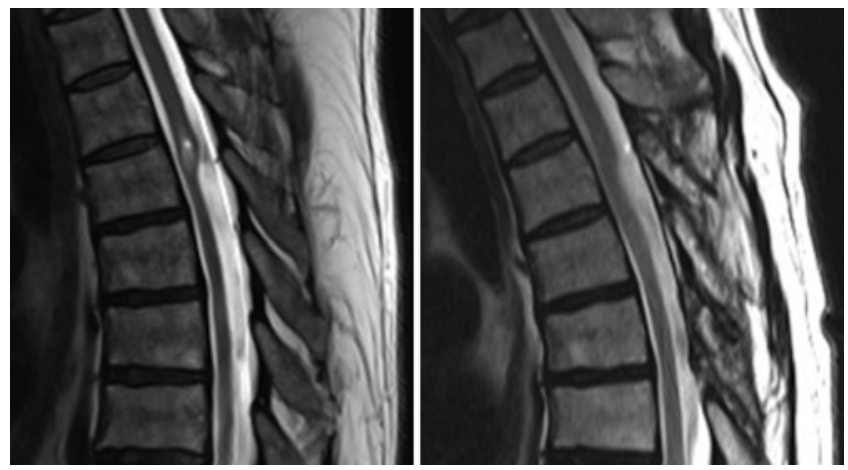

FIG. 5. Preoperative (left) and postoperative (right) MR images of a resected thoracic dorsal intradural arachnoid cyst. 
TABLE 3. Summary of published series of spinal arachnoid cysts in adults highlighting demographic and clinical features, imaging modalities utilized, and outcomes

\begin{tabular}{|c|c|c|c|c|c|c|c|c|c|}
\hline $\begin{array}{l}\text { Authors } \\
\& \text { Year }\end{array}$ & $\begin{array}{c}\text { No. } \\
\text { of } \\
\text { Pts }\end{array}$ & $\begin{array}{l}\text { Mean } \\
\text { Age } \\
\text { (yrs) }\end{array}$ & $\begin{array}{l}\text { Female } \\
\text { Sex }\end{array}$ & Presentation (\% pts) & Imaging & Location & $\begin{array}{l}\text { Surgical Treatment } \\
\text { (\% pts) }\end{array}$ & $\begin{array}{c}\mathrm{FU} \\
\text { (mos) }\end{array}$ & Outcome (\% pts) \\
\hline $\begin{array}{l}\text { Wang } \\
\text { et al., } \\
2003\end{array}$ & 21 & 52 & $38 \%$ & $\begin{array}{l}\text { Pain }(76 \%) \text {, sphincter } \\
(24 \%), \text { myelopathy } \\
(52 \%)\end{array}$ & MRI only & $\begin{array}{l}10 \text { dorsal tho- } \\
\text { racic, } 4 \text { ventral } \\
\text { thoracic, } 2 \\
\text { dorsal cervical, } 2 \\
\text { ventral cervical, } \\
3 \text { dorsal lumbar }\end{array}$ & $\begin{array}{l}\text { Laminectomy w/ cyst } \\
\text { fenestration \& } \\
\text { radical cyst wall } \\
\text { resection, plus } \\
\text { syrinx-subarach- } \\
\text { noid shunting }\end{array}$ & 17 & $\begin{array}{l}\text { No cyst recurrences } \\
\text { during the FU } \\
\text { period. Symptoms of } \\
\text { weakness (100\%), } \\
\text { hyperreflexia }(91 \%) \text {, } \\
\text { \& incontinence }(80 \%) \\
\text { were more likely to } \\
\text { improve than neuro- } \\
\text { pathic pain }(44 \%) \& \\
\text { numbness }(33 \%) \text {. }\end{array}$ \\
\hline $\begin{array}{l}\text { Bassiouni } \\
\text { et al., } \\
2004\end{array}$ & 16 & 43.6 & $52 \%$ & $\begin{array}{l}\text { Pain }(50 \%) \text {, myelopa- } \\
\text { thy }(62 \%)\end{array}$ & $\begin{array}{l}\text { MRI \& CTM in } \\
11 \text { cases }\end{array}$ & 12 dorsal thoracic & $\begin{array}{l}\text { Laminectomy/lami- } \\
\text { noplasty w/ total } \\
\text { excision of cysts } \\
<5 \text { levels, other- } \\
\text { wise generous } \\
\text { fenestration }\end{array}$ & 38.4 & $\begin{array}{l}\text { MRI FU: no recurrence } \\
\text { of the cyst was ob- } \\
\text { served in any patient. }\end{array}$ \\
\hline $\begin{array}{l}\text { Funao } \\
\text { et al., } \\
2012\end{array}$ & 12 & 39.7 & $42 \%$ & $\begin{array}{l}\text { Pain }(42 \%), \text { weak- } \\
\text { ness }(33 \%), \text { gait } \\
\text { ataxia }(58 \%), \\
\text { paresthesia }(67 \%), \\
\text { sphincter }(50 \%)\end{array}$ & $\begin{array}{l}\text { CTM \& cine } \\
\text { MRI }\end{array}$ & 12 thoracolumbar & $\begin{array}{l}\text { Laminectomy w/ total } \\
\text { resection }(58 \%), \\
\text { closure of dural } \\
\text { defect w/o cyst, } \\
\text { resection }(42 \%)\end{array}$ & 56 & $\begin{array}{l}\text { No recurrence of the } \\
\text { SEAC during the FU } \\
\text { period. Improvement } \\
\text { in the mJOA score. }\end{array}$ \\
\hline $\begin{array}{l}\text { Viswana- } \\
\text { than } \\
\text { et al., } \\
2017\end{array}$ & 14 & 52.1 & $36 \%$ & $\begin{array}{l}\text { Weakness }(79 \%), \\
\text { gait ataxia }(100 \%), \\
\text { paresthesia }(86 \%), \\
\text { sphincter }(28.6 \%), \\
\text { myelopathy } 71.4 \%\end{array}$ & MRI only & $\begin{array}{l}12 \text { thoracic, } 1 \\
\text { cervicothoracic, } \\
1 \text { thoracolumbar }\end{array}$ & $\begin{array}{l}\text { Cyst wall fenestra- } \\
\text { tion \& partial } \\
\text { resection }\end{array}$ & 22 & $\begin{array}{l}\text { Median improvement in } \\
\text { mJOA score of } 2.0 \\
(1.3 E 3.0)(p<0.001) \\
\text { w/ respect to the } \\
\text { preop scores. }\end{array}$ \\
\hline $\begin{array}{c}\text { French } \\
\text { et al., } \\
2017\end{array}$ & 10 & 60 & $66 \%$ & $\begin{array}{l}\text { Pain }(10 \%), \text { gait } \\
\text { ataxia }(90 \%), \text { par- } \\
\text { esthesia }(60 \%) \text {, } \\
\text { sphincter }(20 \%)\end{array}$ & $\begin{array}{l}\text { MRI \& cine- } \\
\text { mode } \\
\text { bSSFP MRI } \\
\text { in } 3 \text { pts }\end{array}$ & Unspecified & $\begin{array}{l}\text { Fenestration }(60 \%) \text {, } \\
\text { complete excision } \\
(40 \%)\end{array}$ & 4.4 & $\begin{array}{l}\text { Follow-up MRI \& } \\
\text { subjective symptom } \\
\text { assessment. }\end{array}$ \\
\hline $\begin{array}{l}\text { Present } \\
\text { series }\end{array}$ & 16 & 57 & $75 \%$ & 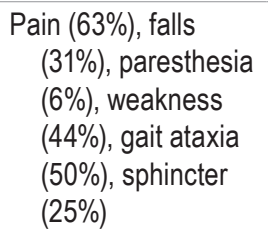 & $\begin{array}{l}\text { MRI \& CTM in } \\
\quad 5 \text { pts }\end{array}$ & $\begin{array}{l}10 \text { dorsal thoracic, } 2 \\
\text { ventral thoracic, } \\
\text { dorsal cervical, } 1 \\
\text { ventral cervical, } \\
1 \text { dorsal lumbar, } \\
1 \text { ventral lumbar }\end{array}$ & $\begin{array}{l}\text { Total cyst excision } \\
(79 \%) \text {, fenestra- } \\
\text { tion/marsupializa- } \\
\text { tion only (14\%), } \\
\text { fenestration \& } \\
\text { ligation (8\%) }\end{array}$ & 8.2 & $\begin{array}{l}\text { Improvement in SF-36 } \\
\text { parameters across } \\
\text { all quality-of-life } \\
\text { parameters. }\end{array}$ \\
\hline
\end{tabular}

bSSFP = balanced steady-state free precision; CTM = CT myelography; pt = patient; SEAC = spinal epidural arachnoid cyst.

sions. The benign disorder is quite rare and has a poorly understood pathogenesis, especially in the absence of a history of trauma or infection. While cystic malformations in the spine are often encountered in the pediatric age group, especially in association with various congenital disorders, only a few reported series in the literature have attempted to characterize adult SACs. In this study, we excluded the pediatric age group due to uncertainty regarding clinical symptoms, and presence of congenital disorders which might further obscure the clinical picture, as well as familial SAC. ${ }^{1,14,21}$ In our series only 1 patient had a remote history of significant trauma, and 2 patients had a diagnosis of multiple sclerosis. None of the patients had a history of meningitis or prior spine surgery. Also of interest in our series is that over three-quarters of the patients were female. While this could imply a sex predilection when taken in isolation, sex distribution in published series varied significantly., ${ }^{2,6,28,29}$ This marked variation could possibly be due to the small series but might actually refute an actual sex predilection (Table 1). The mean presenting age for our patients was 53.4 years (range 34-91 years), which is in keeping with that in other series, reflecting a more common presentation in the 5th and 6th decades of life. ${ }^{6,28,29}$

A characteristic feature of SACs is their anatomical distribution, having a strong predilection to the dorsal thoracic spine, usually intradural. This location is invariably more common than all other locations combined. Less common locations are extradural, ventral, lumbar, and, least commonly, cervical (Table 2). Our results reflect 
those of other published reports (Table 3). The peculiar distribution led authors to suspect that ventral arachnoid cysts could represent a special subgroup with different pathogenesis. Bassiouni et al. noted that all patients with ventral SACs in their series were younger, had greater craniocaudal extension, and exhibited intracystic tough fibrous septae that were not encountered with primary dorsal lesions. This led to their hypothesis that ventral SACs represent a special subgroup arising after adhesive arachnoiditis due to traumatic subarachnoid hemorrhage. ${ }^{2}$ Except for the greater craniocaudal extension, the other features of ventral SACs were not seen in our series. Another previously reported feature of SACs that was not validated in our series is their association with syringomyelia, whereas only 2 of our patients had a small associated syrinx on presentation. ${ }^{3}$

\section{Radiological Diagnosis}

Diagnosis of an SAC represents the greatest challenge in the management of this disorder. In most practices, thin-slice MRI represents the imaging modality of choice for diagnosis and follow-up. MRI is the diagnostic test of choice because of its ability to accurately demonstrate the anatomical location and the extent and relationship of the arachnoid cyst to the spinal cord..$^{26} \mathrm{MRI}$ also has the advantage over CT myelography of visualizing intrinsic cord changes and atrophy that can be used for prediction of neurological outcome. ${ }^{11}$ The classic scalpel sign commonly seen with SACs represents the abrupt buckling or change in contour of the spinal cord. ${ }^{22}$ Other less specific imaging findings like vertebral scalloping or widening of the vertebral pedicle have also been reported, especially with chronic, large SACs. ${ }^{10,16}$ SACs and arachnoid pathologies in general are also known to have a causative association with syringomyelia, which can aid in radiological diagnosis. ${ }^{8}$ In our series, however, only 2 patients $(12 \%)$ harbored a small associated syrinx. Specificity of MRI in diagnosing SACs, however, is debated, especially because of a very similar radiological picture of an even rarer disorder, ventral spinal cord herniation. The modality also has some limitations with SACs given their thin cyst walls and identical signal characteristics of surrounding CSF. Improved visualization of arachnoid webs and cystic formations can be expected with novel high-resolution MRI sequences, such as constructive interference in steady states (CISS) and cine-mode steady-state free-precession imaging (SSFP) studies. However, specificity and superiority to conventional imaging techniques are yet to be validated. $6,24,25$

Being an invasive imaging technique, CT myelography is usually reserved for diagnosis after inconclusive findings on MRI. ${ }^{27}$ The modality has the relative advantage in its ability to localize the connection between the SAC and the main subarachnoid space as well as quantifying the degree of free-flowing CSF between the 2 compartments. Myelography is not conclusive in SACs, as rapid filling of the cyst can result in loss of the interface between the 2 compartments and concealment of the cyst boundaries. Neither modality is therefore conclusive in diagnosing SAC. ${ }^{4}$ In our series, all patients were referred with MRI studies that invariably demonstrated the spinal cord or thecal sac displacement. However, radiological interpretation was only conclusive for an SAC in 16 patients (73\%). In 2 patients the MRI interpretation favored VSCH and was equivocal in the remaining 4 cases. Only 6 patients in our series underwent CT myelography, mainly to rule out VSCH. Interestingly, radiological interpretation favored an SAC only in 3 patients. VSCH was deemed more likely in 2 patients, and in 1 patient, CT myelography findings were inconclusive. While imaging findings were nondiagnostic in some patients, all patients in our series with inconclusive findings on imaging were found to harbor a dorsal intradural SAC on surgical exposure. Our findings therefore reveal a low specificity of both modalities in diagnosing SACs. Realizing the challenges in differentiating the 2 disorders on radiographic imaging, Schultz et al. proposed relying on 2 indirect signs, namely the contour of dorsal cord indentation on sagittal plane, and presence or absence of CSF signal ventral to the cord.$^{24}$ In our experience, however, even with applying those criteria, differentiating spinal arachnoid cysts from VSCH can be challenging (Fig. 1).

\section{Treatment and Outcomes}

The main lines of management of spinal arachnoid cysts comprise complete total resection, fenestration/marsupialization, disconnection from the main arachnoid space, cystosubarachnoid/cystoperitoneal shunting, or a combination. In our practice, laminoplasty is usually adopted to gain access to thoracic spine lesions in order to avoid delayed kyphosis seen after laminectomy. ${ }^{15,31}$ Exposure usually extends 1 extra level rostral and/or caudal to the cyst, allowing for adequate exposure. The goal of surgery is excision of the cyst with spinal cord or thecal sac relaxation and free-flowing CSF proximally and distally. To the best of our knowledge, no prior study has directly compared the success and recurrence rates among different surgical techniques. Recent studies reported sustained recovery after cyst deflation and disconnection from the main subarachnoid space through minimally invasive approaches to avoid complications of an extensive laminectomy.,18 It is believed that cyst excision with complete cyst wall resection, when technically feasible, provides the least chances of recurrence. ${ }^{9}$ In our experience, laminoplasty allows for complete cyst excision to minimize the chances of recurrence while avoiding delayed kyphosis encountered after conventional laminectomy. All our patients had sustained improvement of symptoms except for 1 patient who underwent cyst fenestration due to the poorly accessible ventral location. In this patient, symptoms temporarily improved for 2 months, followed by relapse and reappearance of the cyst on follow-up imaging studies. Shunting of the cyst was recommended to the patient, but the patient declined. There is a strong association between SACs and syringomyelia due to aberrant CSF flow dynamics. Holly and Batzdorf reported neurological improvement and reduction in syrinx cavity size after resection of dorsal thoracic SAC in 8 patients. ${ }^{8}$ In our cohort, a very small associated syrinx was noted in 2 patients, which resolved on followup MRI studies (Fig. 5).

In this study, we shed light on a rather rare spinal disorder and illustrate the pitfalls in diagnosis and surgical 
management. Our results reflect those of other series in the literature (Table 3). We also included patient-reported outcomes to reliably appraise the impact of surgery for symptomatic SAC alongside postoperative radiological changes. Limitations in our study include the small number of cases and short follow-up. The short follow-up also limited our ability to assess the recurrence rates in surgically treated SACs. While long-term clinical and radiological surveillance could ascertain the recurrence rates, in our practice, long-term follow-up was not possible, given continued symptomatic improvement in most patients with the exception of one with a ventral SAC. Our study was also limited in appraising patient-reported outcomes. While newer, more specific scores such as the Oswestry Disability Index and modified Japanese Orthopaedic Association (mJOA) scoring system are now routinely implemented in our practice, the SF-36 score, although relatively nonspecific, was consistently recorded for all patients in our cohort over the study period and was therefore used in our study. Myelography also was not routinely performed in every case, which limited our ability to evaluate the sensitivity and specificity of the imaging modality in diagnosing the SACs. The small number of patients also precluded a meaningful statistical analysis of patient-reported outcomes. Finally, despite its benign nature, an SAC represents a diagnostic and therapeutic challenge. In the absence of standard guidelines, management is largely dependent on surgeon's experience and institutional practice, which greatly influence the treatment and follow-up strategies. Our review provides insight into the presentation, management, and natural course of SAC at a single institution.

\section{Conclusions}

Radiological findings, although helpful, cannot reliably differentiate SACs from other spinal disorders such as VSCH. In symptomatic patients with clinical and imaging findings suggestive of an SAC, surgical exploration with complete resection is the treatment of choice. Treatment is usually well tolerated, carries a low risk of complications, and provides the best chance for optimal recovery.

\section{References}

1. Aarabi B, Pasternak G, Hurko O, Long DM: Familial intradural arachnoid cysts. Report of two cases. J Neurosurg 50:826-829, 1979

2. Bassiouni H, Hunold A, Asgari S, Hübschen U, König HJ, Stolke D: Spinal intradural juxtamedullary cysts in the adult: surgical management and outcome. Neurosurgery 55:13521360, 2004

3. Clifton AG, Ginsberg L, Webb WJ, Valentine AR: Idiopathic spinal arachnoid cyst and syringomyelia. Br J Radiol 60:1023-1025, 1987

4. Dietemann JL, Filippi de la Palavesa MM, Kastler B, Warter JM, Buchheit F: Thoracic intradural arachnoid cyst: possible pitfalls with myelo-CT and MR. Neuroradiology 33:90-91, 1991

5. Fortuna A, Mercuri S: Intradural spinal cysts. Acta Neurochir (Wien) 68:289-314, 1983

6. French H, Somasundaram A, Biggs M, Parkinson J, Allan R, Ball J, et al: Idiopathic intradural dorsal thoracic arachnoid cysts: a case series and review of the literature. J Clin Neurosci 40:147-152, 2017
7. Funao H, Nakamura M, Hosogane N, Watanabe K, Tsuji T, Ishii K, et al: Surgical treatment of spinal extradural arachnoid cysts in the thoracolumbar spine. Neurosurgery 71:278-284, 2012

8. Holly LT, Batzdorf U: Syringomyelia associated with intradural arachnoid cysts. J Neurosurg Spine 5:111-116, 2006

9. Jensen F, Knudsen V, Troelsen S: Recurrent intraspinal arachnoid cyst treated with a shunt procedure. Acta Neurochir (Wien) 39:127-129, 1977

10. Kendall BE, Valentine AR, Keis B: Spinal arachnoid cysts: clinical and radiological correlation with prognosis. Neuroradiology 22:225-234, 1982

11. Krings T, Lukas R, Reul J, Spetzger U, Reinges MH, Gilsbach JM, et al: Diagnostic and therapeutic management of spinal arachnoid cysts. Acta Neurochir (Wien) 143:227235, 2001

12. Kriss TC, Kriss VM: Symptomatic spinal intradural arachnoid cyst development after lumbar myelography. Case report and review of the literature. Spine (Phila Pa 1976) 22:568572,1997

13. Lake PA, Minckler J, Scanlan RL: Spinal epidural cyst: theories of pathogenesis. Case report. J Neurosurg 40:774-778, 1974

14. Menezes AH, Hitchon PW, Dlouhy BJ: Symptomatic spinal extradural arachnoid cyst with cord compression in a family: case report. J Neurosurg Spine 27:341-345, 2017

15. Menku A, Koc RK, Oktem IS, Tucer B, Kurtsoy A: Laminoplasty with miniplates for posterior approach in thoracic and lumbar intraspinal surgery. Turk Neurosurg 20:27-32, 2010

16. Nakashima H, Imagama S, Yagi H, Kato F, Kanemura T, Sato $\mathrm{K}$, et al: Clinical and radiographical differences between thoracic idiopathic spinal cord herniation and spinal arachnoid cyst. Spine (Phila Pa 1976) 42:E963-E968, 2017

17. Nath PC, Mishra SS, Deo RC, Satapathy MC: Intradural spinal arachnoid cyst: a long-term postlaminectomy complication: a case report and review of the literature. World Neurosurg 85:367.e1-367.e4, 2016

18. Neo M, Koyama T, Sakamoto T, Fujibayashi S, Nakamura T: Detection of a dural defect by cinematic magnetic resonance imaging and its selective closure as a treatment for a spinal extradural arachnoid cyst. Spine (Phila Pa 1976) 29:E426E430, 2004

19. Paramore CG: Dorsal arachnoid web with spinal cord compression: variant of an arachnoid cyst? Report of two cases. J Neurosurg 93 (2 Suppl):287-290, 2000

20. Perret G, Green D, Keller J: Diagnosis and treatment of intradural arachnoid cysts of the thoracic spine. Radiology 79:425-429, 1962

21. Rabb CH, McComb JG, Raffel C, Kennedy JG: Spinal arachnoid cysts in the pediatric age group: an association with neural tube defects. J Neurosurg 77:369-372, 1992

22. Reardon MA, Raghavan P, Carpenter-Bailey K, Mukherjee S, Smith JS, Matsumoto JA, et al: Dorsal thoracic arachnoid web and the "scalpel sign": a distinct clinical-radiologic entity. AJNR Am J Neuroradiol 34:1104-1110, 2013

23. Rohrer DC, Burchiel KJ, Gruber DP: Intraspinal extradural meningeal cyst demonstrating ball-valve mechanism of formation. Case report. J Neurosurg 78:122-125, 1993

24. Schultz R Jr, Steven A, Wessell A, Fischbein N, Sansur CA, Gandhi D, et al: Differentiation of idiopathic spinal cord herniation from dorsal arachnoid webs on MRI and CT myelography. J Neurosurg Spine 26:754-759, 2017

25. Shimizu H, Tominaga T, Takahashi A, Yoshimoto T: Cine magnetic resonance imaging of spinal intradural arachnoid cysts. Neurosurgery 41:95-100, 1997

26. Silbergleit R, Brunberg JA, Patel SC, Mehta BA, Aravapalli SR: Imaging of spinal intradural arachnoid cysts: MRI, myelography and CT. Neuroradiology 40:664-668, 1998

27. Srinivasan VM, Fridley JS, Thomas JG, Omeis I: Nuances in 
localization and surgical treatment of syringomyelia associated with fenestrated and webbed intradural spinal arachnoid cyst: a retrospective analysis. World Neurosurg 87:176-186, 2016

28. Viswanathan VK, Manoharan SR, Do H, Minnema A, Shaddy SM, Elder JB, et al: Clinical and radiologic outcomes after fenestration and partial wall excision of idiopathic intradural spinal arachnoid cysts presenting with myelopathy. World Neurosurg 105:213-222, 2017

29. Wang MY, Levi AD, Green BA: Intradural spinal arachnoid cysts in adults. Surg Neurol 60:49-56, 2003

30. Ware JE Jr, Sherbourne CD: The MOS 36-item short-form health survey (SF-36). I. Conceptual framework and item selection. Med Care 30:473-483, 1992

31. Yasuoka S, Peterson HA, MacCarty CS: Incidence of spinal column deformity after multilevel laminectomy in children and adults. J Neurosurg 57:441-445, 1982

\section{Disclosures}

Dr. Dahdaleh: consultant for Stryker, Spinal Elements, and DePuy.

\section{Author Contributions}

Conception and design: Hitchon, Fam, Dahdaleh, Menezes. Acquisition of data: Fam, Noeller. Analysis and interpretation of data: Hitchon, Fam, Woodroffe, Helland, Noeller. Drafting the article: Fam, Woodroffe, Helland. Critically revising the article: Hitchon, Fam, Woodroffe, Helland, Dahdaleh. Reviewed submitted version of manuscript: Hitchon, Fam, Woodroffe, Helland, Menezes. Study supervision: Hitchon, Dahdaleh, Menezes.

\section{Correspondence}

Patrick W. Hitchon: University of Iowa Hospitals and Clinics, Iowa City, IA. patrick-hitchon@uiowa.edu. 